\title{
Study of Radiation Protection for Elekta Medical Linear
}

\section{Accelerator}

\author{
Noaman MF*, El-Khatib $\mathrm{AM}^{\star *}$, Rezk Samia $A^{*}$, Daabis $\mathrm{WM}^{*}$
}

\begin{abstract}
The incidence of cancer throughout the world is increasing with the prolonged life expectancy that has resulted from improvements in standards of living. About half of all cancer patients receive radiotherapy, either as part of their primary treatment or in connection with recurrences or palliation. The International Atomic Energy Agency (IAEA) has estimated that approximately 2500 teletherapy machines were in use in 1998 in developing countries and that 10000 such machines may be needed by 2015 . The preparation of this Safety paper was initiated as a result of an expected increase in the construction of radiotherapy facilities, and in response to Member States that have requested practical guidance regarding the design and shielding of such facilities. In this work, The Harshaw Model 4500 Manual TLD Reader was used for Thermo Luminescence Dosimetry (TLD) by using a set of 20 chips Dosimeter TLD-100. A comprehensive set of measurements were performed for five different sites inside and outside the accelerator. The obtained results showed agreement with published data in some location while the results of the working staff site were within the limits of the recommended permissible dose where it was about 0.5 $\mathrm{m}$ Sievert per year.
\end{abstract}

Key words: Radiotherapy, TLD, Elekta, Harshaw, Sievert.

\section{INTRODUCTION}

Radiation exposure limits or standards were introduced as early as the start of this century when the potential hazards of radiation were realized. One of the first standard setting bodies was the International Commission on Radiological Protection (ICRP), which continues its
These reports form the basis for many national protection guidelines. In the United States, the National Council on Radiation Protection and Measurements (NCRP) has functioned as a primary standard-setting body through its separate publications. One of the agencies with regulatory powers function through its series of publications. in this country is the Nuclear Regulatory

\footnotetext{
* Medical Physics Unit, Faculty of Medicine, Alexandria University, Egypt.

** Physics Department, Faculty of Science, Alexandria University, Egypt.
} 
Commission (NRC), which has control over the use of all reactor-produced materials (e.g., ${ }^{60} \mathrm{CO}$ and ${ }^{192} \mathrm{Ir}$ ). The naturally occurring radioactive materials (e.g., radium and radon) and $\mathrm{x}$-ray machines are regulated by individual states. ${ }^{2}$

\section{1- Dose equivalent}

Because the biological effects of radiation depend not only on dose but also on the type of radiation, the dosimetric quantity relevant to radiation protection is the dose equivalent $(H)$. It is defined as:

$$
H=D . Q
$$

Where $D$ is the absorbed dose and $Q$ is the quality factor for the radiation.

The SI unit for both dose and dose equivalent is joules per kilogram, but the special name for the SI unit of dose equivalent is sievert (Sv).

$$
1 \mathrm{~Sv}=1 \mathrm{~J} / \mathrm{kg}
$$

If dose is expressed in units of rad, the special unit for dose equivalent is called the rem.

$$
H(\text { rem })=D(\text { rad }) \cdot Q
$$

Because $Q$ is a factor and has no units,

$$
1 \mathrm{rem}=10^{-2} \mathrm{~J} / \mathrm{kg}
$$

The use of quality factor in radiation protection is analogous to the use of relative biological effectiveness (RBE) in radiobiology.

\section{2- Low-level radiation effects}

A vast literature exists on the biological effects of radiation. Discussions pertinent to radiation protection can be found in reports of the United Nations Scientific Committee on the Effects of Atomic Radiation. ${ }^{3}$

Whereas large doses of radiation produce identifiable effects within a relatively short period, the effects are difficult to ascertain at low doses (e.g., less than $10 \mathrm{cGy}$ ). The difficulty is due mainly to the extremely low frequency with which these effects might occur. The statistical problems are enormous in identifying small effects in 'the constant presence of spontaneously occurring effects. However, certain effects have been demonstrated in humans 
and other mammals at dose lower than those required to produce acute radiation syndrome but greatly in excess of dose limits recommended by the standards setting bodies. Thus exposure to low-level radiation may produce (a) genetic effectsradiation-induced gene mutations, chromosome breaks, and anomalies; (b) neoplastic diseases-incidence of leukemia, thyroid tumors, and skin lesions; (c) effect on growth and development-adverse effects on fetus and young children; (d) effect on life span-diminishing of life span or premature aging; and (e) cataractsopacification of the eye lens.

The harmful effects of radiation may be classified into two general categories: stochastic effects and nonstochastic effects. The $\mathrm{NCRP}^{4}$ defines these effects as follows.

A stochastic effect is one in which "the probability of occurrence increases with increasing absorbed dose but the severity in affected individuals does not depend on the magnitude of the absorbed dose. In other words, a stochastic effect is an all or non-phenomena such as the development of a cancer or genetic effect. Although the probability of such effects occurring increases with dose their severity does not A nonstochastic effect is one "which increases in severity with increasing absorbed dose in affected individuals, owing to damage to increasing number of cells and tissues." Examples of nonstochastic effects are radiation-induced degenerative changes such as organ atrophy, fibrosis, lens opacification, blood changes, and decrease in sperm count.

Whereas no threshold dose can be predicted for stochastic effects, it is possible to set threshold limits on nonstochastic effects that are significant or seriously health impairing. However, for the purpose of radiation protection, a cautious assumption is made that "The dose-risk relationship is strictly proportional (linear) without threshold, throughout the range of 
dose equivalent and dose equivalent rates

of importance in routine radiation protection."

Many analysts believe that these two assumptions may overestimate the biological effects at low dose levels. Some have proposed a linear quadratic doseresponse curve that assigns relatively reduced effects to low doses. However, in the absence of more reliable data it seems prudent to adopt a conservative model, the non threshold linear response, for predicting low dose effects. For further discussion of dose-response models, the reader is referred to references. ${ }^{[5-8]}$

\section{Effective dose equivalent limits}

$\mathrm{NCRP}^{4}$ recommendations on exposure limits of radiation workers are based on the following criteria: (a) at low radiation levels, the nonstochastic effects are essentially avoided; (b) the predicted risk for stochastic effects should not be greater than the 'average risk of accidental death among workers in "safe" industries; and (c)
ALARA principle should be followed, for which the risks are kept as low as reasonably achievable, taking into account social and economic factors.

\subsection{Occupational and public dose limits}

Dose equivalent limits for occupational and public are given as recommended by the NCRP ${ }^{4}$. These limits do not include exposure received from medical procedures or the natural background. Radiation workers are limited to an annual effective dose equivalent of $50 \mathrm{mSv}$ (5 rem) and the general public is not to exceed one-tenth of this value $(0.5 \mathrm{rem})$ for infrequent exposure and $1 \mathrm{mSv}$ (0.1 rem) for continuous or frequent exposure. Higher limits are set for some organs and areas of the body that involve nonstochastic effects and are less sensitive to radiation than others. For example, the annual occupational dose equivalent limit to the lens of the eye is $150 \mathrm{mSv}$ (15 rem) and to other organs is $500 \mathrm{mSv}$ (50 rem). 
It may be noted that the NCRP has In present study two types of linear discontinued its previous recommendation accelerators were considered:

of the age-proration formula for the 1- Elekta Precise Treatment System ${ }^{\mathrm{TM}}$, cumulative limit, i.e., (age- 18) x 5 rem. The new guidance is that the numerical value of the individual worker's lifetime effective dose equivalent in tens of $\mathrm{mSv}$ (rem) does not exceed the value of his or her age in years.

Students under the age of 18 who may be exposed to radiation as a result of their educational or training activities should not receive more than $1 \mathrm{mSv}$ (0.1 rem) per year.

\section{MATERIAL AND METHODS}

\section{Machines}

Fig. (1) with 4,6 and $15 \mathrm{MV}$ photons and from 4 till $18 \mathrm{MeV}$ electrons. It provides variable field sizes from $4 \times 4$ to $40 \times 40$ at $100 \mathrm{~cm} \mathrm{SSD.}$

Variable X-ray dose rate can be changed manually or via the digital interface protocol.

Multileaf collimators (MLC) and asymmetric jaws provide manual and automatic beam shaping for conformal therapy. There is availability of arc therapy. Virtual wedge is also present.

\subsection{Linacs}




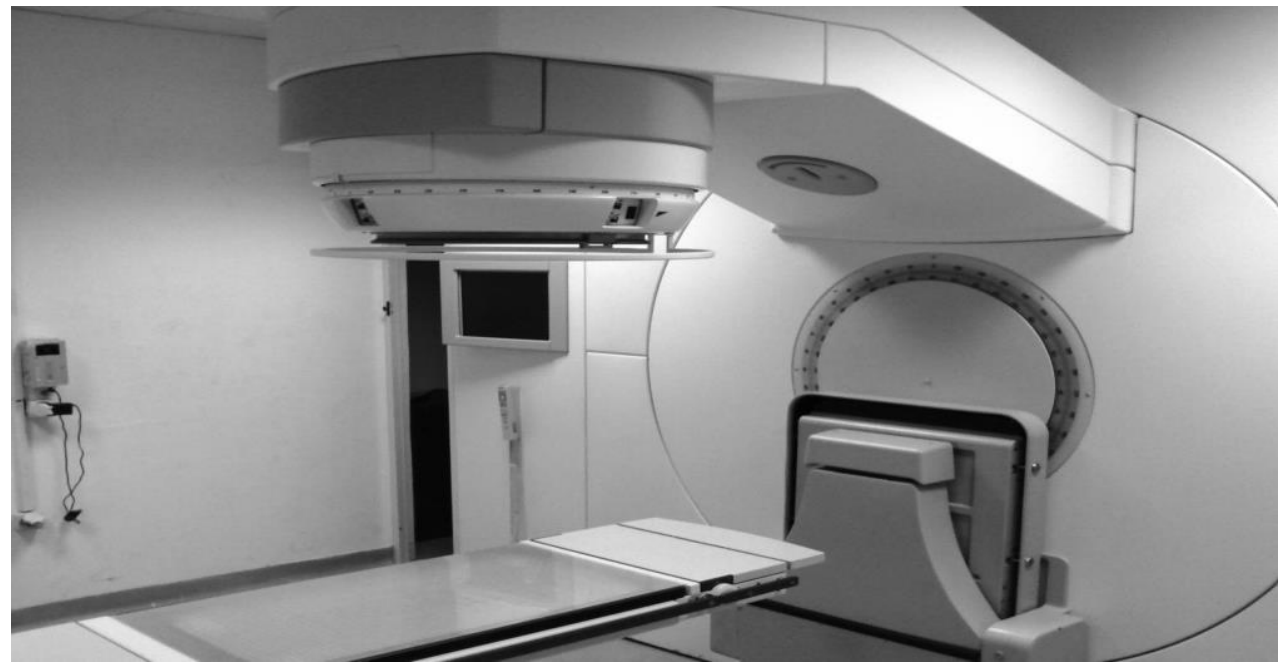

Fig. (1) Elekta Precise Treatment System ${ }^{\mathrm{TM}}$

2- The SL 15 Philips linear accelerators

Fig. (2) has 6 and $10 \mathrm{MV}$ X-rays and electron from 4 till $15 \mathrm{MeV}$. This machine has independent jaws and dynamic wedge.

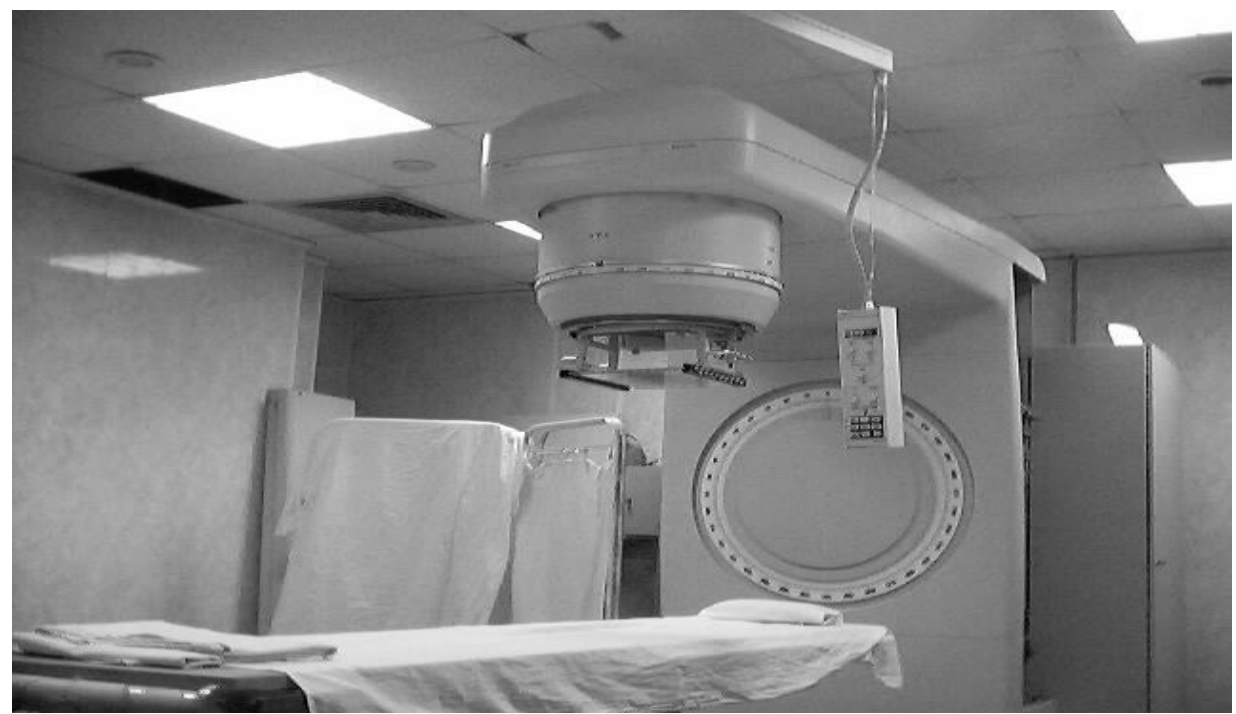

Fig. (2) SL 15 Philips linear accelerators 
1.2 Thermo Luminescence Dosimetry (TLD)

The Harshaw Model 4500 Manual TLD Reader with WinREMS Fig. (3) is a stateof-the-art, tabletop instrument used for thermoluminescence dosimetry (TLD) measurement of a wide variety of TL materials in many forms and sizes. This model incorporates two Photomultiplier Tubes in a sliding housing, with both planchet and hot gas (nitrogen or air) heating methods. The TL element may be heated by hot gas or by a planchet. Hot gas is used for Whole Body and Environmental TL Cards and Extremity Dosimeters (Chipstrates $^{\mathrm{TM}}$ and Ringlets ${ }^{\mathrm{TM}}$ ), while the planchet is used for unmounted TL elements: chips, disks, rods, and powders.

The system consists of two major components: the TLD Reader and the Windows Radiation Evaluation and Management System (WinREMS) software resident on a personal computer (PC), which is connected to the Reader via a serial communications port.

\subsubsection{TLD Reader}

The gas heating system uses a stream of hot nitrogen or air at precisely controlled, linearly ramped temperatures to a maximum of $400^{\circ} \mathrm{C}$ to simultaneously heat two Chipstrates in a Carrier Card or two positions in a four-chip TLD card. Four-chip cards then are moved automatically into position for asecond read cycle to complete the card. The hot gas heating under closed loop feedback control and the superior electronic design produces consistent and repeatable glow curves over a wide dynamic range. This means the card will last longer and can be used more times.

The planchet system uses electric resistance heating with the same closed loop feedback system to produce temperatures to $400^{\circ} \mathrm{C}$ in the standard unit and $600^{\circ} \mathrm{C}$ with the high temperature option. The Reader's basic external components include a front control panel 
consisting of a start button, three LED temperature to maintain consistent status lights (Ready, Cycle, and Fault), and performance of the PMT. Nitrogen is routed a power indicator light; a sample drawer through the PMT chamber to eliminate assembly; and a lens drawer. condensation. The TL charge is collected

The rear panel houses a voltage from each chip in 200 data points along the selectable power input module with fuse Time Temperature Profile (TTP). access, a fitting for nitrogen gas tubing, and an RS-232-C serial communication

\subsubsection{WinREMS Application Software}

Windows Radiation Evaluation and port. A power On/Off switch is located on a small panel on the right side of the Reader.

An electronic Reference Light is built into the Drawer for monitoring the performance of the instrument. It is used as a part of a daily QC check and may be read at operator-specified intervals during the normal reading process.

The Photomultiplier Tube (PMT) dosimetric units as Grays or Sieverts or Assembly is cooled to a constant directly in nanocoulomb. 


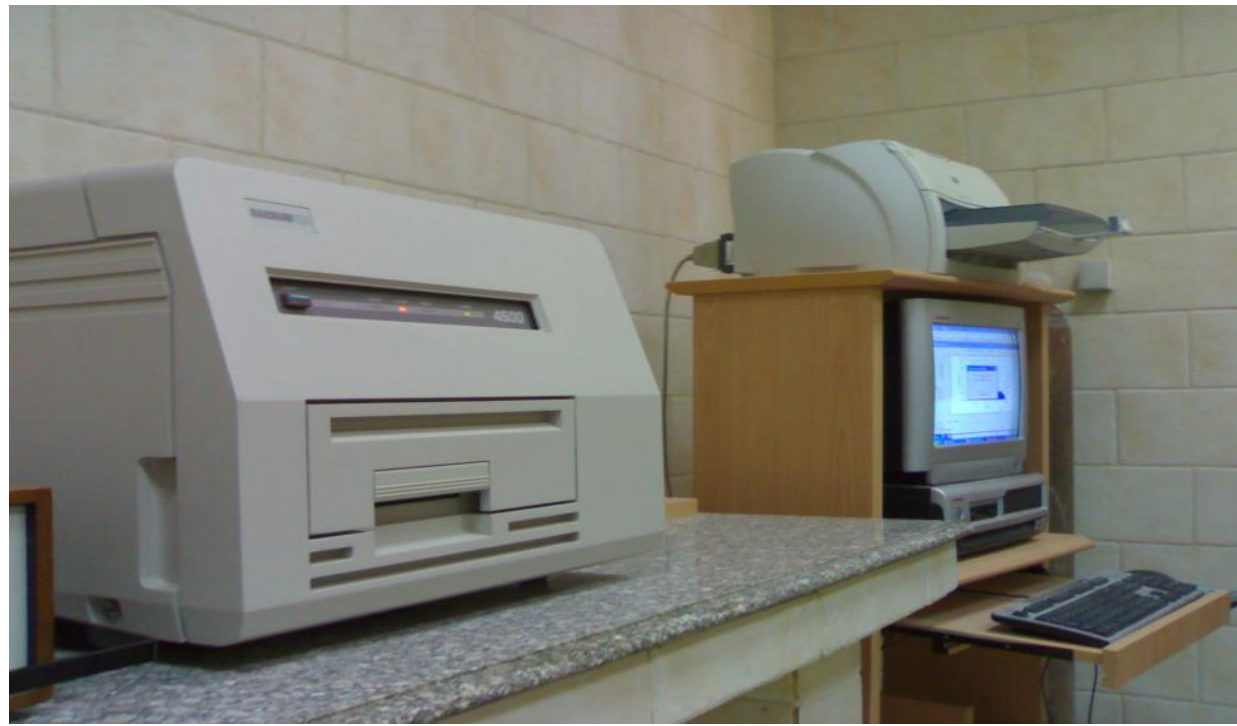

Fig. (3) The Harshaw TLD reader

\subsubsection{Prepare Dosimeters}

In this study, a set of 20 chips according to the following recommended Dosimeter TLD-100 (Fig. (4)) prepared procedure.

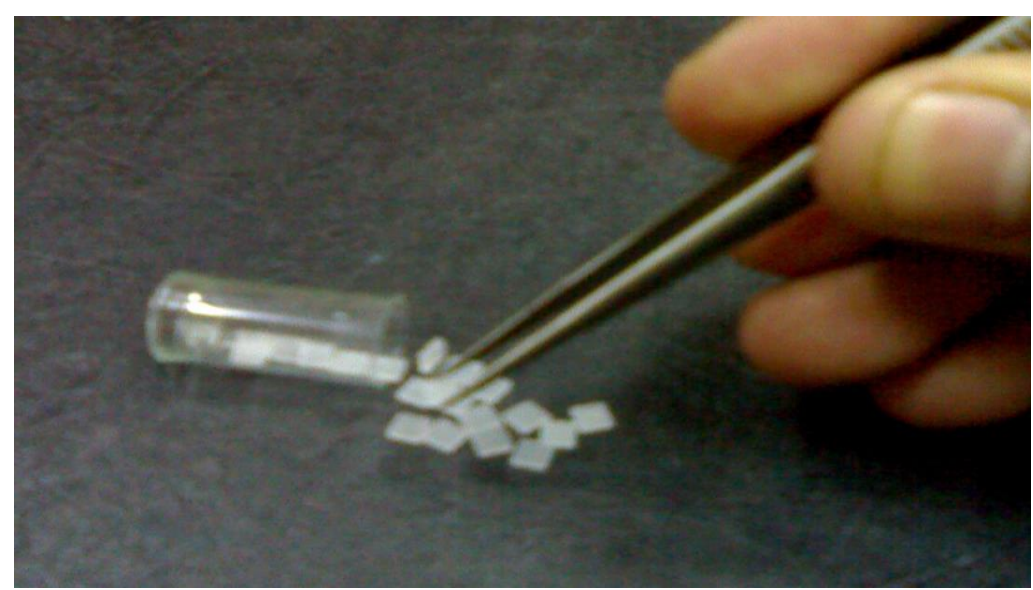

Fig. (4) Handling and preparation of Chips Dosimeter TLD-100 


\subsubsection{Anneal Dosimeters}

Reader annealed the Dosimeters to processing them through a Reader with the clear them of all residual exposure by appropriate TTP, Table (1).

\section{Table (1) TTP Recommendations for Chips dosimeters in planchet readers}

\begin{tabular}{|l|c|}
\hline \multicolumn{1}{|c|}{ Material } & \multicolumn{1}{c|}{$\begin{array}{c}\text { TLD-100 } \\
\text { LiF:Mg,Ti }\end{array}$} \\
\hline Shape & Chips \\
\hline Size & Moderate, High \\
\hline Dose & \\
\hline PRE-HEAT & $50^{\circ} \mathrm{C}$ \\
Temp. & 0 sec. \\
Time & \\
\hline ACQUIRE & $300^{\circ} \mathrm{C}$ \\
Max. Temp. & $33.33^{\mathrm{sec} .}$ \\
Time & $10^{-2}$ \\
Rate & \\
\hline & \\
ANNEAL Temp & $400^{\circ} \mathrm{C}$ \\
Time & $20 \mathrm{sec}$. \\
\hline
\end{tabular}

\subsubsection{Store Dosimeters}

Between preparation (anneal) and TLD irradiator $100 \mathrm{rev} .=4.35 \mathrm{mGy}$

irradiation, the dosimeters are stored in a

subdued UV environment at a temperature

no higher than $30^{\circ} \mathrm{C}$

\subsubsection{Expose Dosimeters}

The Dosimeters exposed to a ${ }^{90} \mathrm{Sr}$ source within two hours of annealing them to $100 \mathrm{r}$ evolutions at Bicorn Model 2210

\subsubsection{Store Dosimeters}

The Dosimeters Stored for the time established (fade time" the time between irradiation and readout for all dosimeters" = 24 hours) in a subdued UV environment at a temperature no higher than $30^{\circ} \mathrm{C}$. After preparing the Dosimeters, The TTP and 
Acquisition parameters are set according to

Table (1)

\subsubsection{Read Dosimeters}

The entire set of dosimeters was read out.

1.2.3.6 Generate Calibration Dosimeters (ECC Calculation)

After reading process complete, the ECC are generated and by changing the upper and lower limits of ECC values (around the mean 1.0) the more deviated chips are rejected from the set and the accepted chips are called Calibration Dosimeters.

\subsubsection{Calibrate reader (RCF} Calculation)

A subset ten chips randomly selected from the entire set of dosimeters (from the Calibration Dosimeters) and exposed to a well known dose (100 rev. $=4.35 \mathrm{mGy})$ by Bicron Model 2210 TLD Irradiator.

\section{A Store Dosimeters}

The Dosimeters Stored for the time established (fade time $=24$ hours) in a subdued UV environment at a temperature no higher than $30^{\circ} \mathrm{C}$.

\section{B Read Dosimeters}

The subsets of dosimeters were read out. After the reading process complete, the RCF are Generated and by accepting the results the RCF is applied to the database.

After Generated ECC and RCF are applied, the entire set of dosimeters now called Field Dosimeters. Thus, these chips are ready to use for radiation measurements

\section{Protection measurement}

The gamma and neutron dose measurements were determined by using the TLD ships For this purpose five locations were chosen to estimate the radiation doses using TLD detector as shown in Fig. (5). The first one was placed on the patient bed, the second was placed on the wall facing the accelerator head in the accelerator room at $2 \mathrm{~m}$ height and $2 \mathrm{~m}$ away from the isocenter, the third was 
placed on the accelerator room at $2 \mathrm{~m}$ in the control room at $2 \mathrm{~m}$ height, and the height and $2.5 \mathrm{~m}$ away from the isocenter, fifth one was placed on the accelerator's the forth was placed on the wall, separating body at $2 \mathrm{~m}$ height.

the accelerator room and the control room,

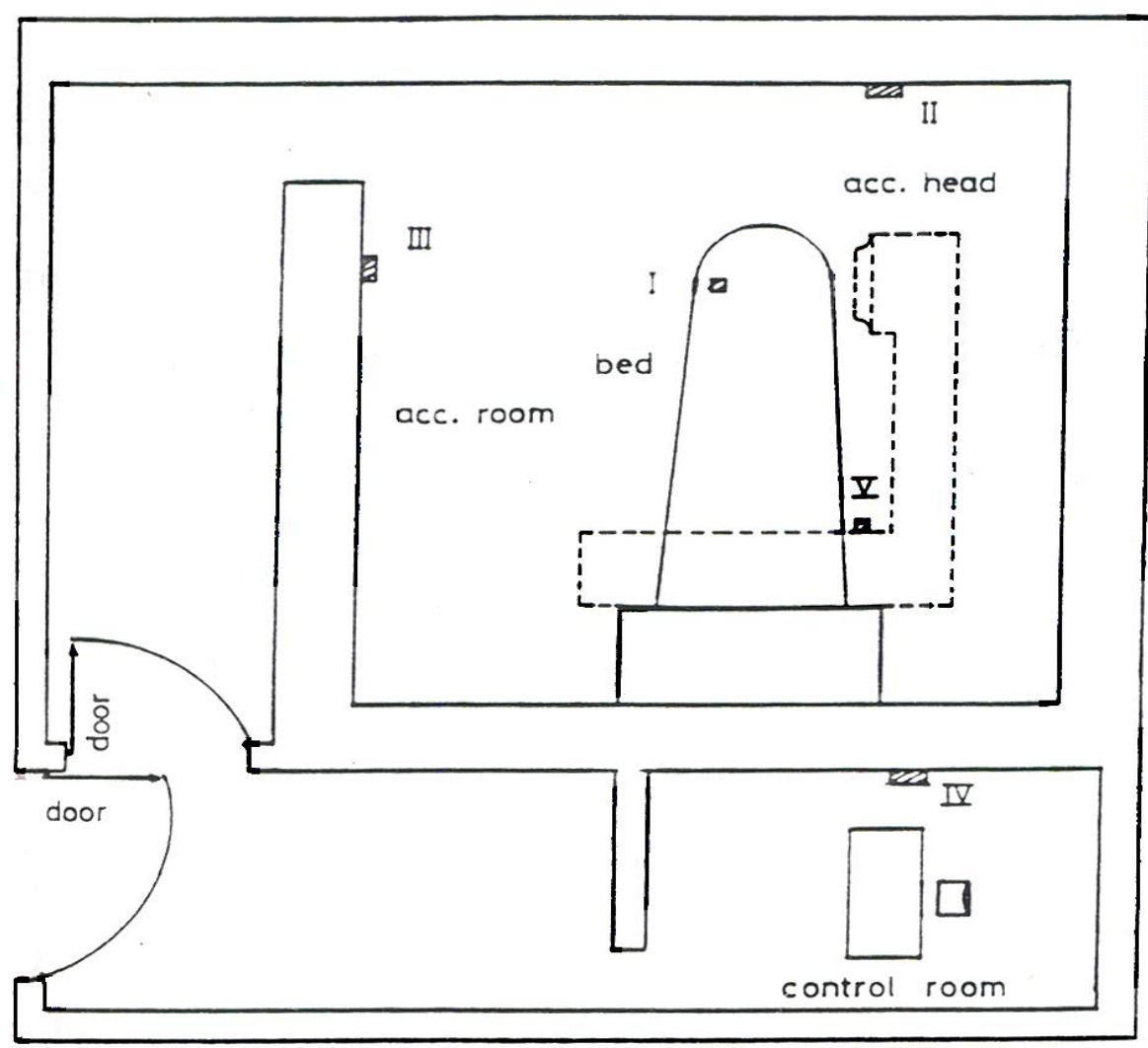

Fig. (5) A schematic diagram illustrating the room layout and the five measurements locations I, II, III, IV, and V 


\section{RESULTS}

TLD measurements were performed in the the following table

pervious motioned locations as shown $\mathrm{n}$

Table (2) Gamma and neutron doses in the accelerator room and the control room

\begin{tabular}{|c|c|c|}
\hline Date and exposure time & Location & Absorbed dose cGy \\
\hline July 2006 & II & $0.72 \times 10^{-5}$ \\
$8 \mathrm{~h}$ & III & $0.3 \times 10^{-5}$ \\
\hline Aug. 2006 & II & $0.75 \times 10^{-5}$ \\
24 h & V & $1.1 \times 10^{-5}$ \\
\hline 3- Sept. 2006 & II & $0.7 \times 10^{-5}$ \\
$48 \mathrm{~h}$ & II & $0.73 \times 10^{-5}$ \\
\hline 4- Oct. 2006 & I & 0.2 \\
$60 \mathrm{~h}$ & II & $0.8 \times 10^{-5}$ \\
\hline Nov. 2006 & IV & $0.05 \times 10^{-5}$ \\
\hline
\end{tabular}

\section{DISCUSSIONS AND CONCLUSIONS}

From table (2), it becomes clear that:

1. The dose rates of Gamma and neutron doses at any location generally decrease with the distance from the isocenter.

2. The equivalent dose rate in the control room is about 0.5 mSievert per year, i.e., it is within the recommended permissible dose.
Finally from the measurements of radiation protection we found that:

The present result at location $\mathrm{I}$ is roughly in agreement with previous data by McGinley et al., ${ }^{9}$ and at location II nad V are comparable with the results obtained by Deye and Young ${ }^{10}$, while the dose in the control room (location IV) is within the limits of the recommended permissible dose for the working staff, where it was about $0.5 \mathrm{~m}$ Sievert per year. 


\section{REFERENCES}

1. IAEA, Radiation protection in the design of radiotherapy facilities, safety reports series no. 47, Printed by the IAEA in Austria September 2006, pp. $1-129$

2. KHAN FM. The Physics of Radiation Therapy, Baltimore, MD: Lippincott, Williams and Wilkins; 2003.

3. Friedell $\mathrm{HI}$, Radiation protection concepts and trade-offs. In: Perception of risk, proceeding of the National Council on Radiation Protection and Measurements. Washington, D: 1980.

4. NCRP. Recommendations on limits for exposure to ionizing radiation. Report No. 91. Bethesda, MD: National Council on Radiation Protection and Measurements. 1987.

5. Elkind MM. The initial part of survival curve: implication for-low-dose-rate radiation responses, Radiate Res. 1977;71:1.

6. Withers HR., Responses of tissues to multiple small dose fractions, Radiate Res. 1977;71:24

7. Brown MM. The shape of the dose response curve carcinogenesis: extrapolation to low doses, Radiate Res. 1977;71:34

8. Upton AC. Radiological effects of low doses: implications for radiological protection, Radiate Res. 1977;71:51

9. McGinaley $\mathrm{PH}$, McLaren JR, Branett BR. Small electron beams in radiation therapy. Radiology. 1979;131, 231-4.

10. Deye JA, Young FC. Newtron production from a $10 \mathrm{MV}$ medical linac. Phy. Med. Bio. 1977;22(1); 90-9. 